\title{
A $A L E X I ́ A D A$ DE ANA COMNENA E A TRADIÇÃO ÉPICA ANTIGA: O RETRATO LITERÁRIO DE ALEIXO I COMNENO ENTRE A FORÇA DE HÉRACLES E O ENGENHO DE ULISSES $^{1}$
}

\section{Rui Carlos Fonseca Universidade de Lisboa. Portugal}

Resumo: Pretende-se analisar a presença homérica na Alexíada de Ana Comnena, em particular o retrato literário de Aleixo, que começa por ser apresentado como Héracles nas vitórias contra os rebeldes Ursélio, Nicéforo Briénio e Basilácio, antes da ascensão ao trono imperial. Após a sua proclamação como imperador dos Romanos, a historiadora faz do pai um herói astuto, qual Ulisses, a procurar defender a nau do império contra os sucessivos ataques do normando Roberto Guiscardo, que se comporta como o Aquiles homérico.

Palavras-chave: Alexíada - Aleixo I Comneno - historiografia bizantina - tradição épica - modelo homérico

\section{ANNA KOMNENE'S $A L E X I A D$ AND THE ANCIENT EPIC TRADITION: THE LITERARY PORTRAIT OF ALEXIOS I KOMNENOS BETWEEN HERAKLES' FORCE AND ODYSSEUS' INGENUITY}

\begin{abstract}
I intend to analyze the Homeric presence in Anna Komnene's Alexiad, particularly the literary portrait of Alexios, who is first presented as Herakles in the victories against the rebels Roussel, Nikephoros Bryennios and Basilakios, before his accession to the imperial throne. After being proclaimed emperor of the Romans, the historian makes his father a wily hero, like Odysseus, seeking to defend the empire's ship against the successive attacks by the Norman Robert Guiscard, who is shown behaving like the Homeric Achilles.
\end{abstract}

Keywords: Alexiad - Alexios I Komnenos - Byzantine historiography - Epic tradition - Homeric model

1 Este artigo foi elaborado no âmbito do meu projecto de pós-doutoramento sobre literatura bizantina, financiado pela FCT-Fundação para a Ciência e a Tecnologia (SFRH/BPD/99542/2014). 
Recibido: 19.02.2020 - Aceptado: 08.15.2020

Correspondencia: Rui Carlos Fonseca

Email: rui@campus.ul.pt

Universidade de Lisboa, Portugal

Direcção Institucional: Centro de Estudos Clássicos

Faculdade de Letras, Universidade de Lisboa

Alameda da Universidade 1600-214, Lisboa, Portugal

Formação

Licenciatura em Línguas e Literaturas Clássicas, Univ. Lisboa (2006)

Doutoramento em Estudos Clássicos, Univ. Lisboa (2013)

Pós-Doutoramento em Estudos Clássicos, Univ. Lisboa (2015 - 2021)

\section{Introdução}

na Comnena, filha do imperador Aleixo I Comneno e de Irene
Ducena, ocupa um lugar de especial destaque na tradição da
historiografia bizantina, a par de outros nomes conhecidos que também registaram os acontecimentos do Império dos Romanos no Oriente e em particular de Constantinopla, a Imperatriz das Cidades. Instruída nas ciências das letras e conhecedora profunda da cultura clássica, Ana Comnena lançou-se à tarefa de relatar a carreira política e militar do seu pai, empreendimento que concluiu em 1148 (cerca de 30 anos após o fim do reinado de Aleixo em 1118) e a que deu o título de Alexíada.

A historiadora declara no prólogo da obra que a "disciplina da história"

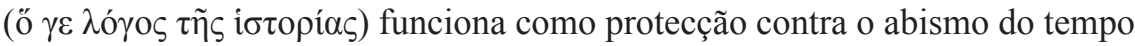
e do esquecimento, razão pela qual pretende "contar os feitos" ( $\tau$ à $\pi \rho \alpha ́ \xi \varepsilon t \zeta$ $\grave{\alpha} \varphi \eta \gamma \eta \dot{\sigma} \sigma \sigma \theta \alpha$ ) do seu pai antes de este ter ascendido ao trono imperial e durante o tempo em que foi imperador. Pretende pois, na sua escrita, "historiar as

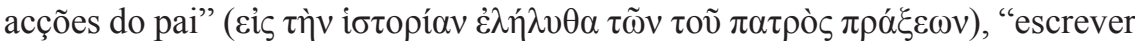

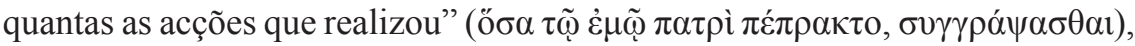

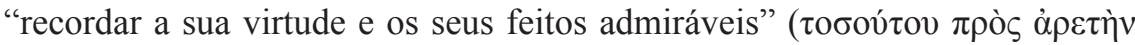

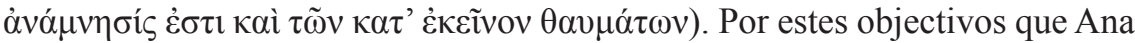
Comnena nos informa, é inegável que estamos perante uma obra que pertence indubitavelmente ao género historiográfico, sem deixar de ser, todavia, um fenómeno de erudição literária no panorama historiográfico bizantino ${ }^{2}$.

2 Muitos têm sido os estudiosos a reconhecer tanto o valor histórico como o carácter literário da Alexíada: e.g. "an account of her father's reign", "one work of historical writing" (Macrides 2000: 63 e 72); "a literary work, in the context of the 
Devido em grande parte ao grego clássico em que a obra é redigida, à influência homérica de muitos dos episódios relatados e ao carácter marcadamente heróico do tema e do protagonista, a Alexíada tem também recebido outras denominações genológicas que a inscrevem na tradição épica. Macrides (2000: 67-68) considera inovadora a obra de Ana Comnena na medida em que se trata de uma história como épica, uma biografia épica ou uma epopeia histórica. Ljubarskij (2000: 174-175 e 177) concorda que essa influência da epopeia é, num certo sentido, um fenómeno novo na historiografia bizantina, não deixando de designar a Alexíada como um verdadeiro relato épico, uma composição baseada numa série de feitos heróicos realizados pela personagem principal. Estudiosos recentes continuam a referir-se à Alexíada como uma "história épica" (Quandahl \& Jarratt 2008: 303 e 319), "biografia épica" (Magdalino 2008: 630), “épica heróica” (Neville 2018: 174), ou identificam-na simplesmente como a epopeia de Aleixo (Kaldellis 2008: 242; Treadgold 2013: 383; Buckley 2014: 3). Independentemente da transversalidade genológica, da terminologia híbrida e do seu valor encomiástico, é indiscutível o estatuto épico, de matiz homérico, que envolve a Alexíada ${ }^{3}$.

Neste ensaio, abordarei precisamente o carácter épico e a influência homérica da Alexíada de Ana Comnena. Para o efeito, tomarei como objecto de análise os feitos heróicos do jovem Aleixo antes da sua ascensão ao trono imperial em 1081, ou seja, as vitórias alcançadas contra Ursélio, Nicéforo

history of Byzantine literature or at least of its historiographic genre", "linked closely to the historiographic and literary tradition" (Ljubarskij 2000: 171 e 176); "Tanto por su título, como por su contenido y su "tono", la Alexíada no es solo una obra histórica, sino que también se la puede concebir como épica" (Marín Riveros 2004: 114); "not a biography but a history centered on a single figure", "literary work", "accurate picture of Alexius' reign", "splendid history", "great history" (Treadgold 2013: 366, 373 e 385); "a straightforward work of history", "a history, albeit an odd history (Neville 2013: 194); "history of the reign of Alexios I Komnenos in Byzantium" (Buckley 2014: 1); "highly biased and politically engaged history", "a masterpiece of Byzantine literature" (Vilimonović 2014: 44); "La Alexíada, según su autora, es historia", "El marco elegido por la autora, el género histórico", "el relato de hechos históricos que informan sobre un periodo concreto" (Díaz Rolando 2016: 29 e 30); "a masterpiece of vivid historical narrative" (Neville 2016: 1); "one of the masterpieces of Byzantine historiography", "long and detailed history of the reign of emperor Alexios Komnenos" (Neville 2018: 174).

Ljubarskij 2000: "Homeric air" (171), “epic air" (174), “epic flavor" (175); Marín Riveros 2004: "ecos homéricos" (114); Neville 2013: "frequent Homeric vocabulary and imagery", "epic cast" (192); Díaz Rolando 2016: "tono general épico de la obra" (25), "indubitable aliento épico" (29). Ver também Cresci (2014: 3-20) sobre a dimensão épico-trágica da Alexíada no que respeita à antítese entre o tempo e a história. 
Briénio e Nicéforo Basilácio, celebradas no Livro I; examinarei também os traços épicos que caracterizam o imperador Aleixo no início do seu reinado, concretamente nas lutas contra Roberto Guiscardo, figura que é introduzida no final do Livro I e que assume protagonismo nos Livros III a VI. Para o objectivo pretendido, deixarei de parte as habituais problemáticas da exactidão factual dos acontecimentos relatados por Ana Comnena, as incongruências históricas que já lhe têm sido apontadas. Centrar-me-ei no estatuto literário da obra, de forma a pôr em evidência os referentes da mitologia e da épica antigas, que contribuem para a apresentação heróica de Aleixo nesta narrativa historiográfica.

\section{Retrato hercúleo de Aleixo antes da ascensão ao trono imperial}

Ana Comnena começa por desenhar um retrato heróico do pai, qual Héracles que passa por vários trabalhos para demonstrar o seu valor, antes de ser aclamado como imperador dos Romanos e "timoneiro da nau do Império" em 1081, o que forçou a abdicação do imperador Nicéforo III Botaniates (como vem relatado no Livro II da Alexíada). As conquistas militares de Aleixo antes da sua ascensão ao trono são engrandecidas pela historiadora como feitos extraordinários, equiparados aos trabalhos do filho de Zeus. Nas suas palavras, o pai é "um Héracles muitíssimo nobre entre os nossos" (I, 9, 6: "Н $\rho \kappa \lambda \varepsilon \dot{\alpha} \alpha \delta \varepsilon$ $\tau \imath v \alpha \kappa \alpha \theta^{\prime} \dot{\eta} \mu \tilde{\alpha} \varsigma \gamma \varepsilon v v \alpha \alpha$ ó $\left.\alpha \alpha \tau o v\right)$. Os três rebeldes com quem se defronta são, desse modo, oponentes notáveis, rivais de grande peso, que representam perigos tremendos para o Império dos Romanos. Cada um é apresentado como um trabalho árduo, superado de forma prodigiosa e engenhosa, por parte de Aleixo.

O normando Ursélio (Roussel de Bailleul), inicialmente ao serviço do imperador Romano IV Diógenes, rebela-se contra o Império dos Romanos, tendo devastado "quase todos os domínios do Oriente", conseguindo mostrarse estrategicamente superior, em experiência e valentia, a quantos lhe fizeram frente $(I, 1,2)^{4}$. Apenas Aleixo foi mais sagaz e o capturou. Este bárbaro começa por ser o objecto de dois símiles mediante os quais é comparado ao

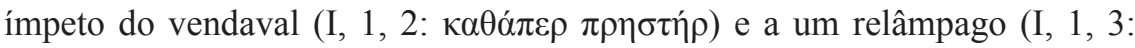

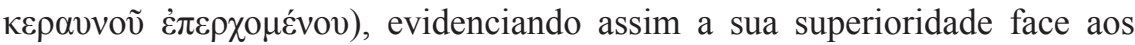
Romanos. A sua derrota pelo jovem Aleixo é, porém, assinalada pelo emprego de outros dois símiles que o mostram como leão subjugado: ora porque posto

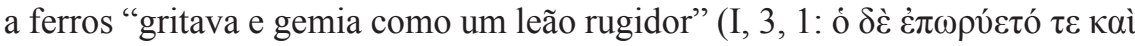

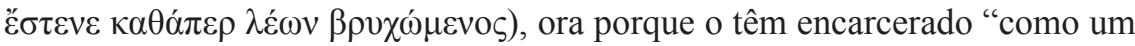




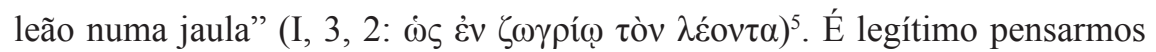
no primeiro dos doze trabalhos de Héracles, a luta com o leão de Némea, o monstro invulnerável que devastava toda a região, tal como Ursélio devastou muitos dos domínios do Oriente. Ademais, Aleixo aprisiona o bárbaro, tal como o herói grego vence o leão depois de conseguir encarcerá-lo na caverna onde habitava. Quando Aleixo leva o rebelde para Constantinopla, a fim de o entregar ao imperador Miguel VII Ducas, a façanha é vista como a descida de Héracles ao Hades para recuperar Alceste e devolvê-la ao mundo dos vivos (I, 3,3). A comparação é tanto mais significativa, porquanto a descida aos Infernos constitui um outro dos trabalhos de Héracles, um dos últimos, que consistia em trazer de lá o cão Cérbero. O herói consegue realizar este trabalho com o auxílio divino, de Hermes e Atena, assim como também Aleixo conseguiu capturar Ursélio com o apoio do emir seljúcida, Tutush I.

Em 1078, o imperador Miguel VII Ducas abdica do trono imperial, sucedendo-lhe Nicéforo III Botaniates, que atribui a Aleixo a segunda missão celebrada na Alexíada: encarregar-se de submeter Nicéforo Briénio, que se havia revoltado contra o imperador deposto e criava grande agitação no Ocidente, reunindo exércitos com a intenção de obter o comando do império ${ }^{6}$. Briénio, duque de Dirráquio, revelava grande mestria na arte da guerra, e era conhecido pela seriedade do seu carácter, coragem e capacidade de persuasão $(\mathrm{I}, 4,3)$. Ana Comnena descreve Briénio e Aleixo como "dois homens nobres, galhardos e semelhantes em força e experiência", "nenhum inferior ao outro em valentia" (I, 5, 1). Porém, no fragor da guerra, Briénio é comparado a "um Ares ou a um Gigante" superando em altura todos os demais (I, 5, 2: ó $\delta \grave{\varepsilon}$ દí

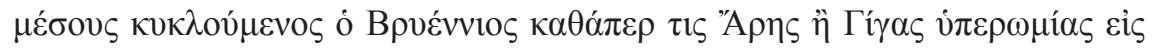

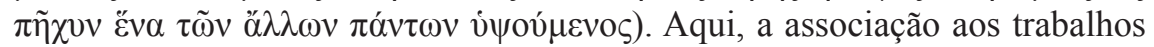
de Héracles é menos óbvia, a não ser que façamos corresponder o Gigante a quem Briénio é comparado a Gérion, o gigante morto pelo herói, e por causa de quem teve de ameaçar os próprios deuses Sol e Oceano, na sua viagem até à ilha de Eriteia, situada no Extremo Ocidente, para lhe roubar os rebanhos de bois. É igualmente possível relacionar Briénio e Alcioneu, o mais poderoso dentre os Gigantes, morto por Héracles no regresso de Eriteia. Noutra das suas aventuras, o herói grego luta contra Ares, por causa da morte de Cicno, filho do deus da guerra. Nas lutas travadas contra o gigante Alcioneu e o

5 Buckley (2014: 53) considera cómica a descrição de Ursélio a vociferar como um leão rugidor. Ao estabelecer o vínculo com o primeiro trabalho de Héracles, Buckley informa também que manter o inimigo preso como um leão cativo é um espectáculo de poder imperial implementado para prevenir derramamento de sangue. 
deus Ares, Héracles conta com o apoio da deusa Atena, assim como Aleixo beneficia da intervenção divina na tentativa falhada de Briénio em matar o futuro imperador $(I, 6,9)$. Apesar da sua supremacia mitificada, equiparada à força de um gigante ou à do deus da guerra, Briénio acaba por ser capturado pelo hercúleo Aleixo e enviado como prisioneiro a Botaniates, conquistando assim o seu segundo prodígio militar.

O adversário seguinte é Nicéforo Basilácio, "um dos homens mais admirados pela sua valentia, coragem, audácia e força" (I, 7, 1), que se ocupa da rebelião de Briénio contra o Império dos Romanos, tendo para o efeito conseguido reunir um exército invencível e ocupado Tessalónica, autoproclamando-se imperador ${ }^{7}$. Aleixo avança contra Basilácio, que é

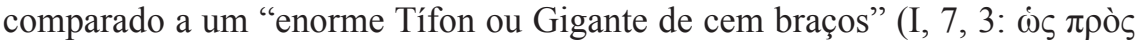

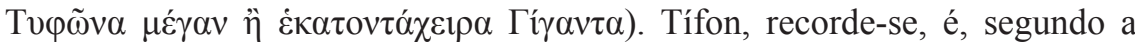
tradição mitológica, um ser monstruoso, mais alto do que as montanhas; os seus braços estendidos tocam o Ocidente, dum lado, e o Oriente, do outro; os seus dedos são cem cabeças de dragão. Este foi o monstro que conseguiu derrotar o próprio Zeus e ocupar o seu lugar, à semelhança de Basilácio que pretendia substituir Botaniates no poder ${ }^{8}$. É este o novo oponente de Aleixo. A historiadora escreve, em mais um símile sugestivo, que o pai avança como

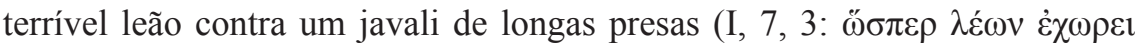

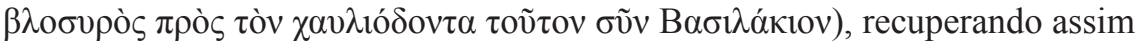
o vínculo mais directo com os trabalhos de Héracles, pois, se dantes Aleixo vencera o leão Ursélio, agora, qual Héracles envergando a pele desse animal feroz, é Aleixo o leão que derrota o javali Basilácio. Ana Comnena reforça essa ligação, aproximando o terceiro adversário do pai ao terceiro trabalho de Héracles, pois o javali mencionado no símile de I, 7, 3 é explicitamente

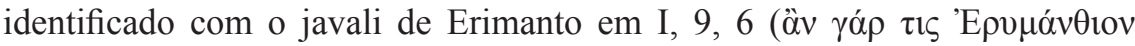

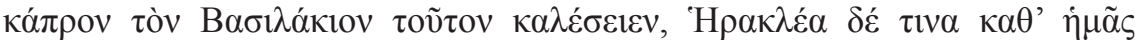

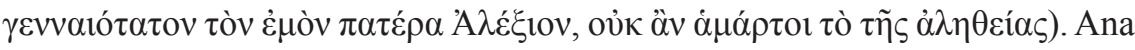
Comnena conclui, desta forma, o relato dos três feitos prodigiosos do pai antes da sua aclamação como imperador, inscrevendo-os no contexto mitológico dos árduos trabalhos de Héracles 9 .

$7 \quad$ Sobre este terceiro rebelde derrotado por Aleixo, ver Buckley (2014: 62-66)

8 O mito de Tífon, incluindo a descrição física e a derrota no combate com Zeus, vem relatado por Hesíodo em Teogonia 820-880.

9 "she frames the episodes as neo-Heraklean labours and moulds them into a progression” (Buckley 2014: 66). 


\section{Retrato odisseico de Aleixo antes da ascensão ao trono imperial}

A par do enquadramento mitológico com o qual Aleixo se vê investido de uma força hercúlea, as três façanhas celebradas no Livro I da Alexíada têm também um carácter épico, sobretudo odisseico. Os perigos militares sucedem-se para o futuro imperador, que os consegue ir superando, a todos, com argúcia e engenho, como é próprio do herói de mil ardis. Na verdade, as vitórias militares de Aleixo dependem amiúde na Alexíada das suas qualidades estratégicas (Buckler 2000: 388-389) ${ }^{10}$.

Aleixo alcança a vitória sobre Ursélio por meio de um engano $(\tau 1$ $\mu \eta \chi \alpha ́ v \eta \mu \alpha$ ): manda cegar publicamente o rebelde sem efectivamente o cegar, e deste modo consegue fazer uma colecta de donativos entre os habitantes de Amásia e obter o dinheiro suficiente para pagar o apoio do emir Tutush (I, 3, 1). Na corte de Constantinopla, Dociano e o imperador Miguel, ao verem os olhos fogosos de Ursélio, ficam espantados, considerando se o ardil do jovem Aleixo não seria um sonho, um prodígio mágico, um artifício estranho (I, 3, 4).

No combate contra as forças de Briénio, Aleixo serve-se de outros dois estratagemas para alcançar a vitória militar. Tendo capturado o cavalo imperial, dá ordem ao exército para que espalhasse a notícia de que Briénio havia caído e morrera por mãos inimigas, sem que, na verdade, isso tivesse acontecido. $\mathrm{O}$ prodígio dos cavalos permite que o falso anúncio se propague como verdade (I, $5,7-9)^{11}$. De seguida, Aleixo consegue pôr as forças de Briénio em debandada graças a uma outra artimanha sua: ele e os Turcos que o acompanhavam fingem fugir do combate, atraindo os adversários para uma emboscada e cobrindo-os com uma densa nuvem de dardos (I, 6, 4-5) $)^{12}$. Ana Comnena serve-se, para o relato deste episódio bélico, de recursos típicos da Ilíada, como o catálogo do exército de Briénio (I, 5, 2), a aristeia de Aleixo, que se lança no meio dos inimigos combatendo corajosamente e desbaratando a formação das fileiras (I, 5, 5), e a observação do exército inimigo a partir do cimo de uma colina (I, 6, 1).

$\mathrm{Na}$ sua marcha contra o rebelde Basilácio, Aleixo monta acampamento junto às margens do rio Vardar, na Macedónia, servindo-se do curso das águas como trincheira natural. Graças à sua vasta experiência de estratega e

10 Sobre a caracterização de Aleixo na Alexíada qual Ulisses homérico, industrioso no pensar, hábil no agir e resiliente face aos perigos, ver e.g. Macrides (2000: 68-69), Treadgold (2013: 367), Buckley (2014: 3-4), Díaz Rolando (2016: 29), Neville (2018: 174-175).

11 Buckley (2014: 59) destaca o carácter espectacular e maravilhoso do episódio do cavalo imperial.

12 Sobre as simulações de fuga na Alexíada como estratégia de emboscada, ver Buckler (2000: 396-398). 
à sua excepcional capacidade de predição, concebeu um plano de precaução contra um eventual ataque dos adversários: durante a noite, abandonou o acampamento com todos os seus soldados, deixando as tendas iluminadas. Afastando-se com o exército armado e alerta, esperou que Basilácio, ao ver as fogueiras acesas, julgasse que Aleixo descansava e o quisesse atacar de imprevisto (I, 7, 4-5). "A predição de meu pai Aleixo não foi vã" (I, 8,

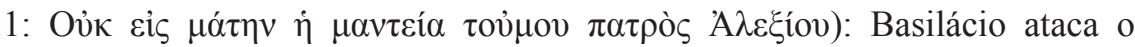
acampamento, descobre o engano e vê cair sobre os seus homens os homens de Aleixo. É possível estabelecer um vínculo temático entre esta façanha e a Doloneia homérica do canto 9 da Ilíada. Ambos os episódios descrevem emboscadas nocturnas protagonizadas por heróis ardilosos, Ulisses e Aleixo. O retrato odisseico de Aleixo é reforçado nas palavras de Ana Comnena ao afirmar que o pai é "eloquente e original como nenhum orador em suas ideias e

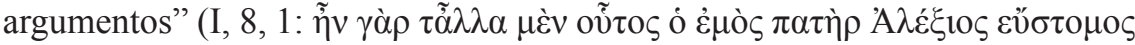

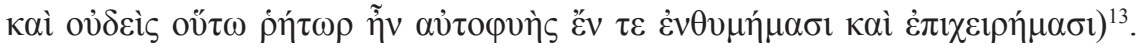
Por fim, a historiadora conclui este terceiro prodígio de Aleixo descrevendo o combate entre o capadócio Gules e Basilácio à semelhança do duelo entre Páris e Menelau, do canto 3 da Ilíada (I, 8, 4). No poema homérico, esse duelo entre o marido e o amante de Helena tem o objectivo de fazer cessar a guerra que vai no décimo ano, mas acaba por ter o efeito inverso de reiniciar a guerra, reactivando novas hostilidades entre Aqueus e Troianos. Na Alexíada, o duelo, inserido na última destas três proezas militares, dá início ao reinado de Aleixo, que vem a ser aclamado imperador pelo próprio exército no Livro II, aclamação que, aliás, vem antecedida pelo anúncio profético de um homem de aspecto sacerdotal (II, 7, 4-7).

\section{Retrato homérico de Aleixo e de Roberto}

O normando Roberto Guiscardo, apresentado no final do Livro I, tornase o primeiro grande adversário de Aleixo I Comneno, durante o seu reinado enquanto imperador dos Romanos. A par do retrato de Aleixo como um Héracles e um Ulisses, Guiscardo surge, na Alexíada, como o Aquiles homérico $^{14}$. O famoso Roberto, conhecido pelas suas intenções tirânicas

13 "what stands out in our rhetorical reading are the copious references to Alexius's uses of persuasive speech and clever stratagems in addition to actual physical combat" (Quandahl \& Jarratt 2008: 322).

14

Além do vínculo entre Aquiles e Roberto, Ljubarskij (2000: 171-172) estabelece também a associação entre Aquiles e Aleixo, não, contudo, do ponto de vista do retrato literário. Para Ljubarskij, Aleixo serve de elemento unificador da Alexíada, assim como Aquiles confere unidade à acção épica da Ilíada. A figura do imperador é, deste modo, um 


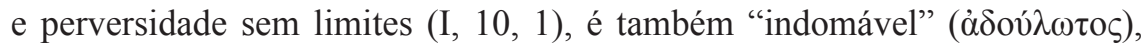

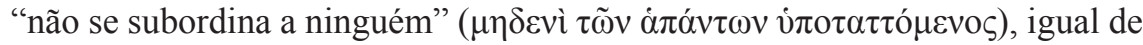
Aquiles na voz, cujo grito provoca a debandada de muitos homens (I, 10, 4:

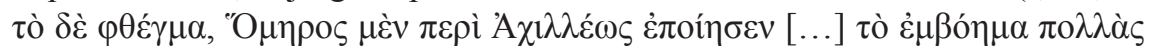

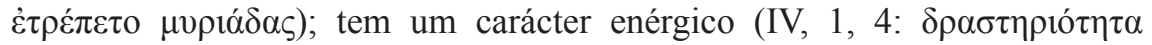

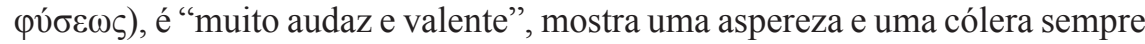
à flor da pele e um coração enfurecido na luta contra o adversário (IV, 8, 2:

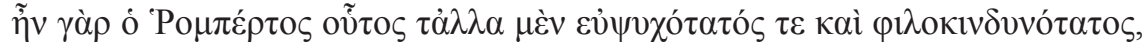

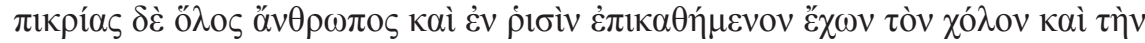

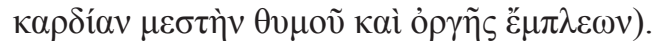

Detentor já de um enorme poderio militar, Roberto arma-se fortemente contra o Império dos Romanos, devido a uma promessa de casamento não cumprida. O imperador Miguel Ducas acordou casar o seu filho Constantino com a filha do bárbaro Roberto, de nome Helena. A promessa de matrimónio, firmada por escrito, porém, nunca chegou a ser mais do que uma promessa, pois o imperador Botaniates desfez o acordo, e o casamento entre Constantino e Helena não se realizou (I, 10, 2; I, 12, 2-4). Achando-se o Império dos Romanos em grandes dificuldades, atacado a Oriente pelos Turcos e a Ocidente pelas tropas de Roberto, o rebelde normando faz guerra contra Bizâncio, porque, escreve Ana Comnena, encontrou "em Miguel um pretexto ao estilo de Pátroclo" (III, 9, 1:

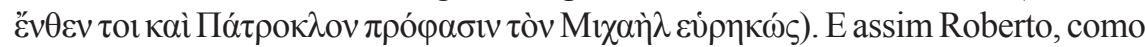
Aquiles, avança para a guerra devido à derrota de Miguel, a que a historiadora associa o referente homérico da morte de Pátroclo ${ }^{15}$.

Os primeiros encontros bélicos com os Normandos (a partir de 1081) são celebrados no Livro IV e têm como causa o cerco de Dirráquio, a antiga Epidamno ${ }^{16}$. Aleixo sai derrotado, escapando com dificuldade da batalha. Protagoniza, porém, um episódio com ressonâncias homéricas ${ }^{17}$. Numa fuga prodigiosa em cima do seu cavalo, como que sustentado por asas e inspirado por força divina $(\mathrm{IV}, 7,2)$, Aleixo recobra novo ânimo ao distinguir no campo

dos principais traços homéricos da obra historiográfica de Ana Comnena.

15 A morte de Pátroclo é uma presença homérica proverbial na Alexíada (Dyck 1986: 114). No âmbito das reconstruções homéricas na Alexíada, para Buckley (2014: 68), conquanto o paralelo não seja exacto, os Normandos funcionam grosseiramente como os Gregos a invadirem Tróia.

16 Sobre o cerco de Dirráquio, ver e.g. Angold (1997: 129-131); Buckler (2000: 398-414); Birkenmeier (2002: 62-70); Theotokis (2014: 154-164); Meško (2019: 147152).

17 Birkenmeier (2002: 62) escreve que: "Anna's account of the battle of Dyrrachion is muddled and filled with Homeric-style anecdotes about Alexios." 
de batalha um soldado que, pelo resplendor das armas, lhe pareceu ser Roberto. Ambos lutam e Aleixo dá-lhe a morte, apenas para descobrir que o homem não era Roberto, mas um dos seus comandantes mais ilustres (IV, 7, 4-5). Ainda que não haja citação ou referência directa, um leitor atento não deixa de pensar num possível eco da morte de Pátroclo por Heitor no canto 16 da Ilíada, no qual o filho de Menécio entra na guerra envergando as armas de Aquiles e sendo inclusive confundido com o Pelida.

Além do carácter engenhoso de Aleixo, da sua habilidade estratégica para encontrar a saída mais oportuna nos momentos mais críticos (IV, 6, 2), outro aspecto do seu retrato literário que o aproxima da figura do Ulisses homérico é o sentimento de profundo respeito pelo divino. Ana Comnena dá conta de que o pai tinha "uma enorme fé em Deus" (V, 4, 8). Essa devoção que lhe é característica não só o diferencia do normando Roberto como também o assemelha ao herói astuto da épica grega. Ulisses é o comandante que enfrenta vários perigos no mar, não se coibindo de saquear povos e cidades com o auxílio da sua tripulação, como é o caso, por exemplo, de Ísmaro, a terra dos Cícones. Ao contrário da tripulação, porém, o herói respeita as leis sagradas dos deuses e, por isso, beneficia do apoio divino, tanto no regresso à pátria (os deuses acordam o seu regresso, no canto I da Odisseia, porque sempre ofereceu sacrifícios a Zeus) como na luta contra os homens arrogantes que lhe assediam a mulher (a vingança é preparada e executada com o apoio de Atena, a sua deusa protectora). Ulisses torna-se o único sobrevivente do raio punidor de Zeus, no episódio da tempestade após a partida de Trinácia, onde os seus companheiros haviam infringido o decreto do deus Sol ao profanarem o gado que lhe estava consagrado.

No início da Alexíada, Ana Comnena relata dois episódios que mostram o pai a beneficiar da graça do altíssimo: uma força divina impede Briénio de concretizar a sua ideia de matar Aleixo $(I, 6,9)^{18}$; e a Divina Providência socorre Aleixo na fuga miraculosa em cima do seu cavalo para escapar às lanças e à perseguição dos Celtas do exército de Roberto (IV, 7, 2; IV, 8, 3). Pelo relato que a historiadora nos apresenta, Aleixo é também o herói que, à frente da nau do império, se predispõe a purificar-se dos actos impiedosos cometidos durante o saque de Constantinopla. A sua ascensão ao poder no ano 1081 faz-se mediante um golpe militar: as suas tropas invadem a capital, dispersam-se pelas ruas e

18 Dick (1986: 115-116) associa este episódio da Alexíada ao episódio do canto primeiro da Ilíada, versos 194-198, em que Atena protege Aquiles impedindo-o de atacar Agamémnon. Ao identificar este referente homérico, Dyck sugere que "Anna both lends plausibility to an inherently implausible situation and invests Alexius with the aura of a divinely protected leader." 
avenidas, saqueando inclusive igrejas e santuários (II, 10, 4). Uma vez detendo o ceptro do poder, o imperador Aleixo penitencia-se publicamente pelos crimes praticados contra as instituições sagradas e por todas as desgraças a que submeteu a cidade. Essa necessidade de purificação vem-lhe, escreve Ana Comnena, do temor a Deus ( seu comportamento torpe e sacrílego possa atrair a cólera de Deus (III, 5, 1:

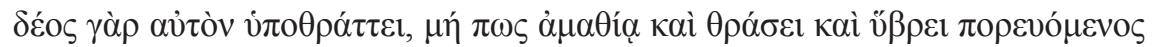

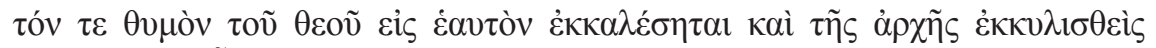

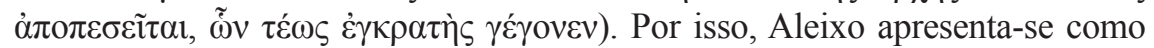
réu ante o sagrado sínodo e aceita cumprir a sentença que lhe é imposta, para

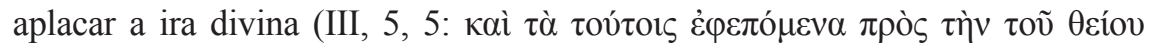
$\grave{\varepsilon} \xi 1 \lambda \dot{\varepsilon} \omega \sigma ı v \dot{\varepsilon} \pi \imath \tau \alpha \dot{\xi} \alpha \nu \tau \tau \zeta)$. Ulisses não só é o herói que vence astutamente vários perigos, como também o herói que tudo faz para se reconciliar com a divindade: consagrará hecatombes a Posídon para se redimir da cegueira que infligiu ao Ciclope; respeita a interdição do deus Sol em Trinácia e escapa ao raio punidor de Zeus; e Atena não lhe causa adversidades no regresso de Tróia como aos Aqueus sacrílegos. Assim também Aleixo se absolve dos crimes cometidos retractando-se perante Deus, para administrar o império com as mãos puras (III,

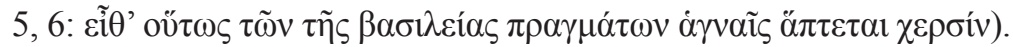

Contrariamente, Roberto sofre infortúnios no mar como consequência do seu comportamento arrogante. No final do Livro III, ao navegar em direcção a Dirráquio para a assediar, uma terrível tempestade de fortes chuvas e ventos que encrespam o mar abate-se súbita e furiosamente sobre a armada como castigo divino: "Mas durante esse tempo, a tempestade não amainou, como se Deus estivesse a descarregar a sua ira contra a arrogância descomedida e presunçosa de Roberto, mostrando, já desde esse primeiro momento, que o

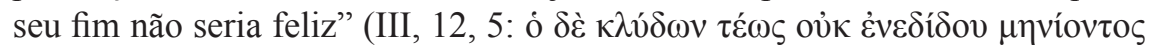

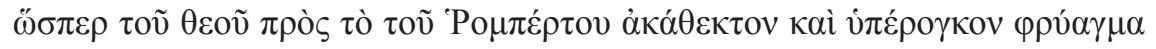

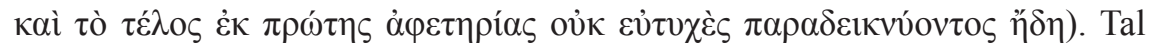
como a tempestade, também a peste e a fome subsequentes se afiguram castigos procedentes do altíssimo. Essa sucessão de infortúnios, porém, não é suficiente para atemorizar o intrépido Roberto, que reúne os sobreviventes da tempestade, reagrupa as tropas e avança para as ruínas da antiga Epidamno (III, 12, 6-8). Ana Comnena parece, portanto, construir na Alexíada um retrato de Roberto semelhante ao dos mortais transgressores, que na Odisseia são severamente punidos pela divindade, como é o caso da tripulação de Ulisses e dos pretendentes de Penélope, marcando, desse modo, um contraste notório entre Aleixo e Roberto no que respeita ao sentimento de devoção a Deus. 
Os dois adversários militares comportam-se como heróis notáveis na guerra. De forma a imprimir-lhes a excelência bélica digna dos poemas homéricos, Ana Comnena descreve as circunstâncias históricas das campanhas em que participam, adornando-as com temas e episódios típicos do género da epopeia antiga. A historiadora serve-se de uma das mais tradicionais técnicas de literatura épica para apresentar longas tiradas de nomes, amiúde de soldados, os catálogos. É, pois, sob a forma de descrição catalógica que são dados a conhecer os exércitos de Briénio (I, 5, 2), as forças de Roberto (I, 16, 1), os títulos e as hierarquias da corte imperial (III, 4, 2-3), os exércitos de Aleixo contra Roberto (IV, 4, 3), os Romanos mortos pelas tropas de Roberto (IV, 6, 7), e os comandantes de Aleixo (V, 5, 7). No Livro IV, são-nos apresentados os conselhos de guerra alternados da parte de Aleixo e de Roberto, ao estilo das assembleias militares de Aqueus e Troianos na Ilíada: dum lado, Aleixo ouve as diferentes opiniões dos chefes do seu exército sobre como agir a respeito de Roberto (IV, 5, 3); doutro lado, logo de seguida, Roberto é investido de plenos poderes pelo seu exército e decide fazer guerra contra Aleixo (IV, 5, 5-7) ${ }^{19}$; por fim, de novo no conselho dos Romanos, Aleixo delibera a melhor estratégia contra as tropas de Roberto $(I V, 6,1)$. No confronto entre os exércitos latinos de Roberto e os exércitos romanos de Aleixo, o comportamento bélico dos dois faz também lembrar as aristeiai militares descritas na Ilíada: Roberto, qual cavaleiro alado, cavalga contra a falange romana, dispersando-a (IV, 6, 7); Aleixo resiste valorosamente aos ataques combinados de três latinos (IV, 6, 8).

Apesar das muitas derrotas sofridas, a guerra contra os Normandos chega ao fim em 1085, ano em que Roberto morre. A sua morte vem anunciada em registo oracular. Ao chegar a Cefalénia, Roberto é vítima de febres intensas e recorda-se da profecia que alguns adivinhos haviam anunciado: "Até Ather estás destinado a submeter tudo; mas quando daí partires para Jerusalém,

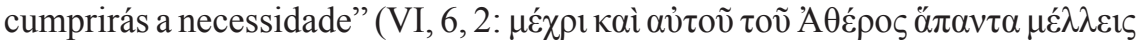

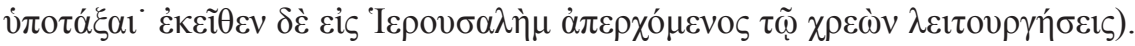
Tal como no Livro III, na navegação para Dirráquio, Roberto vira a sua armada destroçada por uma tempestade que lhe fora infligida como castigo divino, também a sua morte ocorre num episódio de tempestade, durante a travessia em direcção à Apúlia (VI, 6, 3). O matemático Seth havia igualmente vaticinado um oráculo sobre a morte de Roberto: "Um importante inimigo do Ocidente, que muitos problemas causou, subitamente cairá” (VI, 7, 1: $\mu \varepsilon ́ \gamma \alpha \varsigma$

19 No discurso aos seus chefes militares em IV, 5, 5, Roberto usa palavras semelhantes às de Agamémnon em Ilíada II, 204-205, também num episódio de conselho de guerra. 


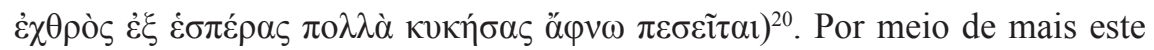
recurso, Ana Comnena aproxima a morte do primeiro grande inimigo do pai à morte de Aquiles, na medida em que também esta vai sendo antecipada ao longo da Ilíada (e.g. as profecias de Tétis e do cavalo Xanto).

A Alexíada é uma obra historiográfica, que, como é próprio desse género bizantino, dispõe e manipula os factos históricos para contar boas histórias ${ }^{21}$, a função encomiástica aliando-se ao processo mimético dos modelos (retóricos e literários) antigos. Tanto o colorido mitológico como o universo homérico ressoam amiúde por toda a Alexíada, redigida e apresentada como a épica de Aleixo. O imperador surge aos olhos dos leitores, de outrora e de hoje, ora como um Héracles que supera trabalhos árduos e é agraciado pelo toque protector da divindade, ora como um Ulisses, timoneiro astuto que procura conduzir a nau do império a bom porto, através de um mar encapelado por sucessivas tempestades. Assim, Ana Comnena "historiciza" a épica e "epiciza" a história; representa o pai, o imperador Aleixo I Comneno, com atributos dignos de um herói, relatando a sua carreia política e conquistas militares como se fossem uma sucessão de prodígios e façanhas notáveis.

\section{REFERÊNCIAS BIBLIOGRÁFICAS}

ANA COMNENA (2016). La Alexíada. Una Historia del Imperio Bizantino Durante la Primera Cruzada, introducción, traducción y notas de Emilio Díaz Rolando. Barcelona: Ático de los Libros.

ANGOLD, M. (1997). The Byzantine Empire, 1025-1204: A Political History. London-New York: Longman.

Annae Comnenae Porphyrogenitae Alexias (1884). Ex Recensione Augusti Reifferscheidii, Volumen I. Lipsiae: In Aedibus B. G. Teubneri.

BIRKENMEIER, J. W. (2002). The Development of the Komnenian Army, 10811180. Leiden-Boston-Köln: Brill.

BUCKLER, G. (2000). Anna Comnena: A Study. Oxford: Oxford University Press.

BUCKLEY, P. (2014). The Alexiad of Anna Komnene: Artistic Strategy in the Making of a Myth. Cambridge: Cambridge University Press.

CRESCI, L. R. (2014). "Citazioni nel proemio dell"“Alessiade" di Anna Comnena: tra ideologia e metodologia storiografica". Parole Rubate: Rivista Internazionale di Studi sulla Citazione, 10, 3-20.

20 Para uma interpretação literária das profecias e das questões astrológicas do Livro VI da Alexíada, ver Vilimonović (2014: 45-50). Ver também a breve referência em Treadgold (2013: 380) sobre as profecias enquanto digressões na narrativa historiográfica.

21 "So good stories always formed a prominent part in Byzantine history writing" (Scott 2010: 253). 
DYCK, A. R. (1986). “Iliad and Alexiad: Anna Comnena's Homeric Reminiscences". Greek, Roman and Byzantine Studies, 27(1), 113-120.

GRIMAL, P. (2004). Dicionário da Mitologia Grega e Romana, tradução de Victor Jabouille, 4. ${ }^{\text {a }}$ ed. Miraflores: Difel.

KALDELlis, A. (2008). Hellenism in Byzantium: The Transformations of Greek Identity and the Reception of the Classical Tradition. Cambridge: Cambridge University Press.

LJUBARSKIJ, J. (2000). "Why Is the Alexiad a Masterpiece of Byzantine Literature?". In Th. Gouma-Peterson (Ed.), Anna Komnene and Her Times (pp. 169-185). New York: Garland Publishing.

MACRIDES, R. (2000). "The Pen and the Sword: Who Wrote the Alexiad?". In Th. Gouma-Peterson (Ed.), Anna Komnene and Her Times (pp. 63-81). New York: Garland Publishing.

MAGDALINO, P. (2008). "The Empire of the Komnenoi (1118-1204)". In J. Shepard (Ed.), The Cambridge History of the Byzantine Empire c. 5001492 (pp. 627-663). Cambridge: Cambridge University Press.

MARÍN RIVEROS, J. (2004), “Ana Comneno en el panorama de la cultura bizantina". Byzantion Nea Hellás, 23, 85-118.

MEŠKO, M. (2019). "Some Thoughts on the Military Capabilities of Alexios I Komnenos: Battles of Dyrrachion (1081) and Dristra (1087)". Graeco - Latina Brunensia, 24(2), 143-161.

NEVILLE, L. (2018). Guide to Byzantine Historical Writing. Cambridge: Cambridge University Press.

--- (2016). Anna Komnene: The Life and Work of a Medieval Historian. New York: Oxford University Press.

--- (2013). "Lamentation, History, and Female Authorship in Anna Komnene's Alexiad". Greek, Roman and Byzantine Studies, 53(1), 192218.

QUANDAHL, E., \& JARRATT, S. C. (2008). “To Recall Him ... Will be a Subject of Lamentation': Anna Comnena as Rhetorical Historiographer". Rhetorica: A Journal of the History of Rhetoric, 26(3), 301-335.

SCOTT, R. (2010). "Text and Context in Byzantine Historiography”. In L. James (Ed.), A Companion to Byzantium (pp. 251-262). West Sussex: Wiley - Blackwell.

THEOTOKIS, G. (2014). The Norman Campaigns in the Balkans, 1081-1118. Woodbridge: The Boydell Press.

TREADGOLD, W. (2013). The Middle Byzantine Historians. New York: Palgrave Macmillan.

VILIMONOVIĆ, L. (2014). "Observations on the Text and Context of Anna Komnene's Alexiad". Belgrade Historical Review, 5, 43-58. 